\title{
Article \\ Genetic Diversity of Trypanosoma cruzi in Panama Inferred by Multi-locus Sequence Typing of Mitochondrial Genes
}

\author{
Jose E. Calzada ${ }^{1,2,+} \mathbb{D}^{\mathbb{D}}$, Franklyn Samudio ${ }^{1,3,+} \mathbb{D}^{\mathbb{D}}$, Corina de Juncá ${ }^{4}$, Vanessa Pineda ${ }^{1}$ (D), Barbara A. Burleigh ${ }^{5, *}$ \\ and Azael Saldaña 1,4,*
}

check for

updates

Citation: Calzada, J.E.; Samudio, F.; de Juncá, C.; Pineda, V.; Burleigh, B.A.; Saldaña, A. Genetic Diversity of Trypanosoma cruzi in Panama Inferred by Multi-locus Sequence Typing of Mitochondrial Genes. Microorganisms 2022, 10, 287. https://doi.org/ $10.3390 /$ microorganisms10020287

Academic Editors: Maria-Jesus Pinazo and Alejandro Gabriel Schijman

Received: 21 December 2021

Accepted: 25 January 2022

Published: 26 January 2022

Publisher's Note: MDPI stays neutral with regard to jurisdictional claims in published maps and institutional affiliations.

Copyright: (C) 2022 by the authors. Licensee MDPI, Basel, Switzerland. This article is an open access article distributed under the terms and conditions of the Creative Commons Attribution (CC BY) license (https:/ / creativecommons.org/licenses/by/ $4.0 /)$.
1 Departamento de Investigación en Parasitología, Instituto Conmemorativo Gorgas de Estudios de la Salud, Panama 0816, Panama; jcalzada@gorgas.gob.pa (J.E.C.); fsamudio@gorgas.gob.pa (F.S.); vpineda@gorgas.gob.pa (V.P.)

2 Facultad de Medicina Veterinaria, Universidad de Panamá, Apartado 3366, Panama

3 Departamento de Genética y Biología Molecular, Facultad de Ciencias Naturales, Exactas y Tecnología, Universidad de Panamá, Apartado 3366, Panama

4 Centro de Investigación y Diagnóstico de Enfermedades Parasitarias (CIDEP), Facultad de Medicina, Universidad de Panamá, Apartado 3366, Panama; juncacorina@yahoo.com

5 Department of Immunology and Infectious Diseases, Harvard School of Public Health, 655 Huntington Ave, Boston, MA 02115, USA

* Correspondence: bburleig@hsph.harvard.edu (B.A.B.); asaldana@gorgas.gob.pa (A.S.)

+ These authors contributed equally to this work.

\begin{abstract}
The objective of this study was to provide information on Trypanosoma cruzi genetic diversity among isolates obtained from different biological sources circulating in endemic areas of Panama. Initial discrete typing units (DTUs) assignment was performed evaluating three single locus molecular markers (mini-exon, heat shock protein 60 and glucose-6-phosphate isomerase genes). Further diversity within TcI lineages was explored using a multi-locus sequence typing approach with six maxicircle genes. Haplotype network analysis and evolutionary divergency estimations were conducted to investigate the genetic relatedness between Panamanian TcI isolates and isolates from different endemic regions in the Americas. Our molecular approach validated that $\mathrm{TcI}$ is the predominant DTU circulating in Panama across different hosts and vector species, but also confirmed the presence of TcIII and TcVI circulating in the country. The phylogenetic tree topography for most Panamanian TcI isolates displayed a high level of genetic homogeneity between them. The haplotype network analysis inferred a higher genetic diversity within Panamanian TcI isolates, displaying eight different haplotypes circulating in endemic regions of the country, and revealed geographical structuring among TcI from different endemic regions in the Americas. This study adds novelty on the genetic diversity of T. cruzi circulating in Panama and complements regional phylogeographic studies regarding intra-TcI variations.
\end{abstract}

Keywords: Chagas disease; Trypanosoma cruzi; genetic diversity; discrete typing units; Panama; Central America

\section{Introduction}

Chagas disease, caused by Trypanosoma cruzi, is a major neglected health problem in Central America, leading to significant economic losses due to reduced productivity from early-age disability and mortality [1]. More than $10 \%$ of people in this region live in Chagas disease risk areas, and nearly 400,000 people are estimated to be infected with this protozoan parasite [2-4].

In Panama, situated in the southernmost part of Central America (Figure 1), Chagas disease seems to adopt clinical and epidemiological features that may differ from the rest of the region. For instance, the main Chagas disease vector in Panama is Rhodnius pallescens; a sylvatic triatomine closely associated with "royal" palm trees (Attalea butyracea) [5-8], 
differing from the main vector species in the rest of the Central American region. Rhodnius pallescens is also the only known vector of Trypanosoma rangeli, a non-pathogenic trypanosome that is transmitted through the saliva of this triatomine [6,9-12] and which is frequently found in blood of both humans and animals in Panama. Interestingly, in animal models, it has been observed that exposure to T. rangeli may modulate immune responses that confer some degree of protection against a subsequent infection with T. cruzi [13-16].

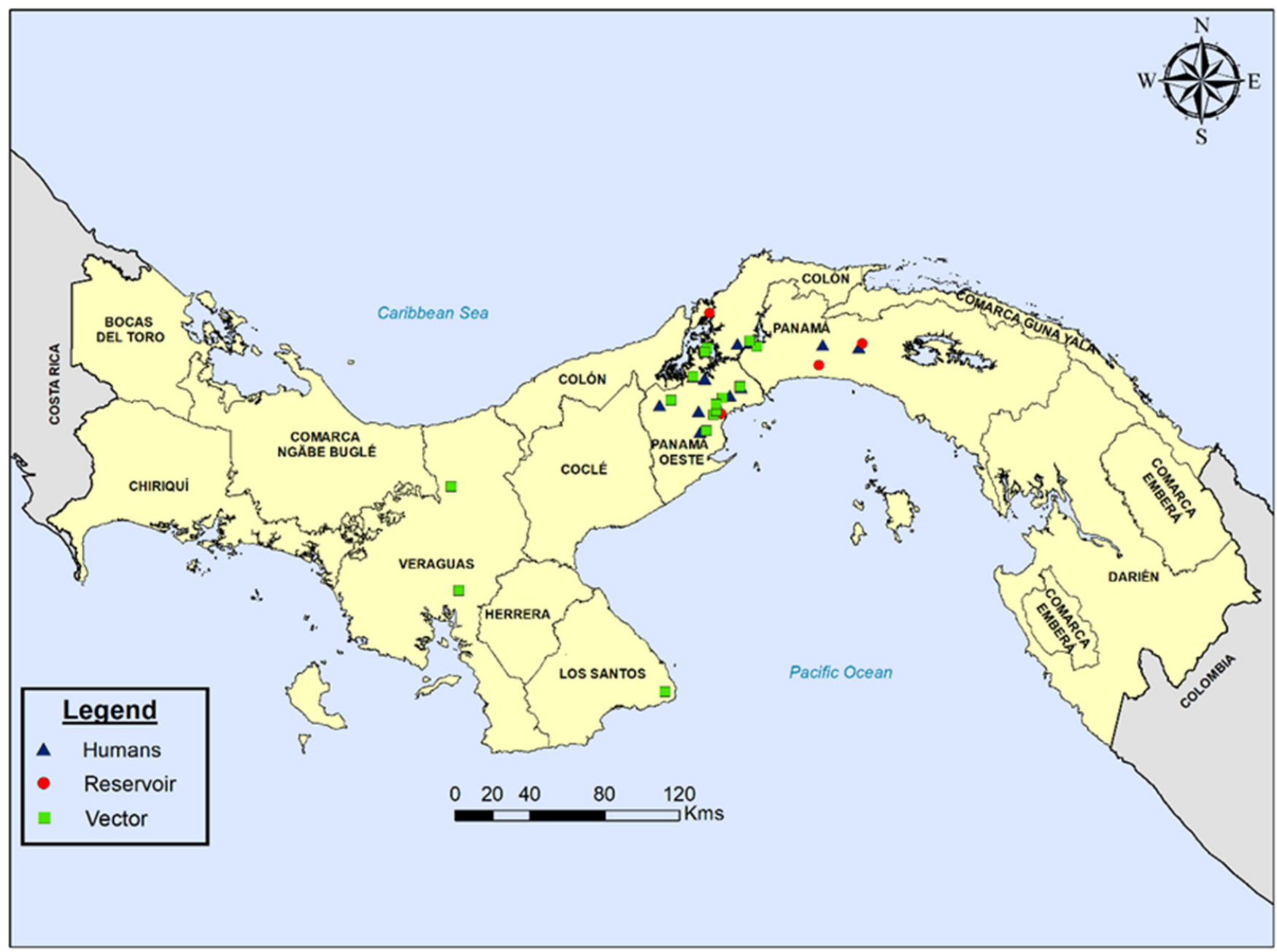

Figure 1. Map of Panama showing the geographical origin and biological source of the 32 Panamanian Trypanosoma cruzi isolates analyzed in this study. Blue triangles represent samples isolated from humans, red circles from reservoirs and green squares from vectors.

Some clinical aspects of Chagas disease in Panama also differ from those documented in South America and, to some extent, to other Central American regions. For example, Chagoma and Romaña's signs during the acute phases of infection are rarely reported $[17,18]$ and parasitemia in humans is low and of relatively short duration compared to acute infections documented in South America [18,19]. Moreover, symptomatic Chagas disease appears to be milder and is often characterized as the cardiotropic form with no evidence of the gastrointestinal manifestations of developing in the chronic stages of infection [18-20]. It has been suggested that these clinical differences might be related to the genetic variability of T. cruzi parasites circulating in Panama and/or to the immunogenetic background of host populations [8]. However, there are no recent studies that address the pathogenesis and clinical manifestations of Chagas disease observed in the country. Furthermore, the genetic structure of $T$. cruzi circulating in the different endemic regions of 
Panama has only been partially investigated, and only at the most basic level of discrete typing units (DTUs) using single locus markers [21-25].

At present, seven DTUs of T. cruzi (TcI-TcVI and Tcbat) are internationally accepted [26-28]. Within each of these groups there is substantial genetic heterogeneity, TcI being the most diverse and widespread in humans, vectors and reservoirs [29,30], as well as the predominant lineage in the Central American region [3,28]. It has been suggested that the geographical heterogeneity observed in Chagas disease pathology, biological behavior, transmission cycles and clinical outcome might be related to genetic variability displayed by this parasite [31,32]. Thus, genotype identification is important for epidemiologic tracking purposes, and as a guide to provide a prognosis of disease progression and/or differential treatment decisions based on the infective strain.

In this regard, few studies have explored the genetic diversity of T. cruzi strains circulating in endemic regions of Panama by surveying human hosts, vectors and animal reservoirs in these regions to understand the epidemiologic importance of genotypes in transmission cycles and disease. Earlier studies have identified TcI as the predominant DTU circulating in Panama, and in many cases associated with disease [21-25]. However, these studies were limited by the low number of samples analyzed from different biological samples (human, vector, animal), the restricted geographical range, the lack of standardization of molecular protocols, as well as the short time span over which samples were collected.

To address this gap, the objective of present study was to provide information on $T$. cruzi discrete typing unit genotypes in isolates obtained from different biological sources circulating in endemic areas of Panama. We also explored the genetic diversity within TcI lineages based on a maxicircle multi-locus sequence typing approach (mtMLST). Haplotype network analysis and evolutionary divergency estimations between mitochondrial sequences were further conducted to investigate the genetic relativeness between Panamanian TcI isolates and isolates from different endemic regions in the Americas.

\section{Materials and Methods}

Panama is a narrow and highly biodiverse biogeographical corridor connecting South and Central America (Figure 1). It has a tropical climate, with relatively high temperatures throughout the year, ranging from $26^{\circ} \mathrm{C}$ to $32{ }^{\circ} \mathrm{C}$, and two marked seasons: Dry Season: January-May; Rainy Season: May-December. The Pan American Health Organization (PAHO) considers Panama an area endemic for Chagas disease where the sylvatic behavior of the main vectors recognized in the country ( $R$. pallescens, Triatoma dimidiata and Panstrongylus geniculatus) complicates current approaches to control vectorial transmission $[4,33]$. These triatomine species are widespread and are responsible for maintaining sylvatic transmission cycles that vary in intensity across different rural and suburban regions of Panama. Compared to other countries from the region, human infections in endemic areas of Panama are low (prevalence ranging 1-4\%) and are mostly associated with sporadic invasion by sylvatic vectors of vulnerable poor-quality housing predominant in rural areas of the country [8-12,34]. Several sylvatic and domestic animal reservoirs have been identified in the country, from which opossums (Didelphis marsupialis) are the most important in the transmission cycle [18]. They share the same natural habitat with vectors (royal palm trees) and due to their synanthropic behavior, opossums favor the connection between sylvatic and peridomestic T. cruzi cycles, particularly in deforested and forest fragmented rural areas of Panama, where there is an increase in vector abundance and increased risk of human infection by T. cruzi $[35,36]$.

\subsection{Sample Collection and T. cruzi Genotyping}

A panel of 32 Panamanian parasite isolates obtained from different epidemiological settings were genotyped (12 from the blood of Panamanian patients with different clinical profiles, 4 from the blood of animal reservoirs and 16 from vectors). Information regarding the clinical case, identification of the isolates, location, and year of isolation is presented in Figure 1 and Table 1. The Panamanian isolates were supplied by the Trypanosomatids Bank 
at CIDEP, Faculty of Medicine, University of Panama and were maintained as epimastigotes in liver infusion-tryptose (LIT) medium supplemented with $15 \%$ fetal bovine serum. Reference strains used in this study were obtained from the Department of Immunology and Infectious Diseases, Harvard School of Public Health. Total genomic DNA was prepared from logarithmic phase cultures using Wizard ${ }^{\circledR}$ Genomic DNA Purification System (Promega, Madison, WI, USA).

Table 1. List of Panamanian Trypanosoma cruzi isolates analyzed in this study with details about their epidemiological data, clinical history and results of discrete typing units (DTUs).

\begin{tabular}{|c|c|c|c|c|c|c|}
\hline Original Code & Host/Vector (Sex, Age) & Locality (Region) & Date & Clinical Status & Outcome & T. cruzi DTU \\
\hline TCH1 & Human (Female, 9y) & Chorrera (WP) & Oct, 1980 & Acute & Chronic & $\mathrm{TcVI}$ \\
\hline $\mathrm{TCH} 2$ & Human (Male, 78y) & Aguas Claras (Colón) & April, 1983 & Asymptomatic & Indetermined & TcI \\
\hline TCH3 & Human (Female, 7y) & Chorrera (WP) & March, 1981 & Asymptomatic & Indetermined & TcI \\
\hline $\mathrm{TCH} 4$ & Human (Male, 29y) & Chilibre (Colón) & July, 1971 & Acute & Unknown & TcI \\
\hline TCH5 & Human (Male, 20y) & Chepo (EP) & July, 1965 & Asymptomatic & Chronic & TcI \\
\hline TCH6 & Human (Male, 42y) & Capira (WP) & Jan, 1987 & Acute & Indetermined & TcI \\
\hline TCH7 & Human (Female, 17y) & Mendoza (WP) & July, 1970 & Asymptomatic & Indetermined & TcI \\
\hline TCH8 & Human (Male, 18y) & Cerro Cama (WP) & April, 1979 & Asymptomatic & Unknown & TcI \\
\hline TCH10 & Human (Female, 13y) & Pacora (EP) & Jan, 1995 & Acute & Indetermined & TcIII \\
\hline TCH12 & Human (Male, 31y) & Bunrunga (WP) & Oct, 2002 & Acute & Unknown & TcI \\
\hline TCH14 & Human (Female, 1y) & Nuevo Arraiján (WP) & Oct, 1973 & Acute & Chronic & TcI \\
\hline TCH15 & Human (Male, 3y) & Capira (WP) & Aug, 1980 & Acute & Chronic & TcI \\
\hline TCR1 & Monkey (Saguinus geoffroyi) & Pacora (EP) & June, 1966 & Asymptomatic & Unknown & TcI \\
\hline TCR2 & Opossum (Didelphis marsupialis) & Chepo (EP) & June, 1966 & Asymptomatic & Unknown & TcI \\
\hline TCR3 & Otter (Lontra longicaudis) & Colon & May, 1973 & Asymptomatic & Unknown & TcI \\
\hline TCR4 & Canine (Canis familiaris) & Chorrera (WP) & 2004 & Acute & Fatal & TcI \\
\hline TCV1 & Panstrongylus geniculatus & Barro Colorado (WP) & 1992 & & & TcI \\
\hline TCV2 & Rhodnius pallescens & Chilibre (Colón) & 1991 & & & TcI \\
\hline TCV3 & Triatoma dimidiata & Barro Colorado (WP) & 1992 & & & TcI \\
\hline TCV4 & Rhodnius pallescens & Cerro Cama (WP) & 1985 & & & TcI \\
\hline TCV5 & Rhodnius pallescens & Chilibre (Colón) & 2011 & & & TcI \\
\hline TCV6 & Rhodnius pallescens & Chorrera (WP) & 2011 & & & TcI \\
\hline TCV7 & Rhodnius pallescens & Chorrera (WP) & 2011 & & & TcI \\
\hline TCV8 & Rhodnius pallescens & Burunga (WP) & 2011 & & & TcI \\
\hline TCV9 & Rhodnius pallescens & Chorrera (WP) & 2011 & & & TcI \\
\hline TCV10 & Rhodnius pallescens & Chorrera (WP) & 2012 & & & TcI \\
\hline TCV11 & Rhodnius pallescens & Capira (WP) & 2012 & & & TcI \\
\hline TCV12 & Rhodnius pallescens & Santa Fe (Veraguas) & 2014 & & & TcI \\
\hline TCV13 & Rhodnius pallescens & Pedasi (Los Santos) & 2016 & & & TcI \\
\hline TCV14 & Rhodnius pallescens & Capira (WP) & 2016 & & & TcI \\
\hline TCV15 & Panstrongylus geniculatus & Montijo (Veraguas) & 2015 & & & TcIII \\
\hline TCV17 & Rhodnius pallescens & Burunga (WP) & 2000 & & & TcI \\
\hline
\end{tabular}

WP: Western Panama; EP: Eastern Panama; DTU: Discrete typing units.

Genotyping was accomplished in a two-stage approach. Initial DTU assignment was performed evaluating the following single locus molecular markers as previously recommended [37]: mini-exon gene, heat shock protein 60 (HSP60)/EcoRV and glucose-6phosphate isomerase (GPI)/ HhaI. All mixtures, amplification conditions and restriction enzyme digestions were previously described [37]. Amplification and RFLP products were visualized on $1.5 \%$ agarose gels containing ethidium bromide, and their sizes were 
estimated by visual inspection using a $50 \mathrm{bp}$ DNA ladder as molecular size marker (New England Biolabs, Ipswich, MA, USA) (Figure 2).

a.

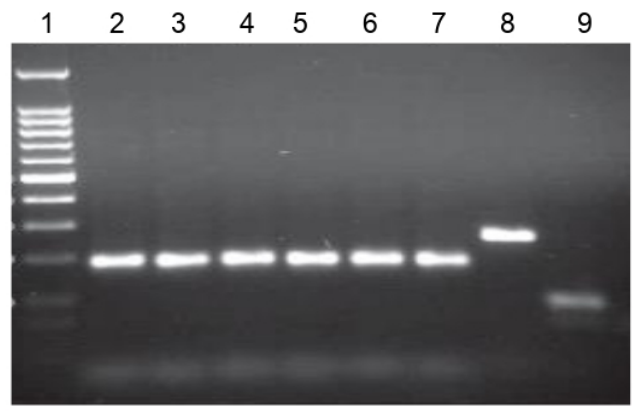

b.

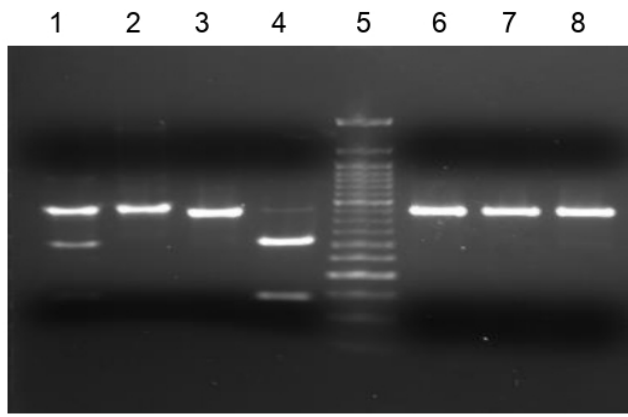

C.

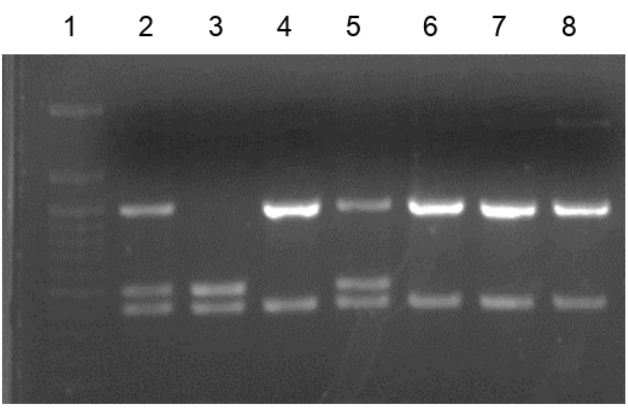

Figure 2. Trypanosoma cruzi genotyping. Initial discrete typing unit (DTU) assignment was performed evaluating the following single locus molecular: mini-exon gene, heat shock protein 60 (HSP60)/EcoRV and glucose-6-phosphate isomerase (GPI)/HhaI: (a) Representative agarose gel for Trypanosoma cruzi mini-exon genotyping. Lane 1: Molecular weight marker 50-bp ladder; Lanes: 2-7: T. cruzi TcI Panamanian isolates; Lane 8: T. cruzi non- TcI Panamanian isolate; Lane 9: T. rangeli control; (b) Representative agarose gel for Trypanosoma cruzi HSP60/EcoRV genotyping. Lanes 1-3: T. cruzi control strains; Lane 4: TCH1; Lane 5: Molecular weight marker 50-bp ladder; Lane 6: TCH2; Lane 7: TCH3; Lane 8: TCH4; (c) Representative agarose gel for Trypanosoma cruzi GPI/Hha1 genotyping. Lane 1: Molecular weight marker 50-bp ladder; Lanes 2-4: T. cruzi control strains; Lane 5: TCH1; Lane 6: TCH2; Lane 7: TCH3; Lane 8: TCH4.

To further explore intra-DTU diversity within Panamanian isolates assigned as TcI, six maxicircle gene fragments were amplified: ND1 (NADH dehydrogenase subunit 1), COII (cytochrome c oxidase subunit II), MURF1 (Maxicircle unidentified reading frame 1, CYT b (cytochrome b), 12S rRNA and 9S rRNA, coding regions. Primers, annealing temperatures and PCR amplification conditions were as previously described [30]. As controls, we also sequenced the following reference T. cruzi TcI strains: Y strain (TcII, isolated from a patient in Sao Paolo, Brazil), Tulahuén strain (TcVI, isolated from Triatoma infestans collected in Tulahuén, Chile), CL Brener strain (TcVI, isolated from Triatoma infestans in Rio Grande Do Sul, Brazil), G strain (TcI, isolated from a naturally infected opossum in Amazon, Brazil) and a recent TcI isolate from an El Salvadorian patient [38]. 
PCR amplification products were separated on $1.0 \%$ agarose gels prepared with $1 \mathrm{X}$ TBE buffer. Resulting DNA bands were excised from agarose gel and purified using the Qiaquick gel extraction Kit (Qiagen, CA, USA) following the manufacturer's instructions. Purified PCR products were sequenced in both directions at the GENEWIZ DNA Sanger Sequencing Service using previously described primers [30]. Nucleotide sequences for all six gene fragments are available in the GenBank database under the accession numbers listed in Table S1.

\subsection{Sequence Editing and Bayesian Phylogenetic Inference}

Chromatograms were edited by the assembling-to-reference tool of UGENE toolkit using a trimming quality value of 35 [39]. For each isolate, maxicircle sequences were concatenated according to their structural arrangement. Multiple sequence alignments were generated by MAFFT software also included in the bioinformatic toolkit UGENE with a maximum number of iterative refinements of 3 and a gap penalty of 1.53 . Using JModelTest 2 [40], the best DNA evolution model was found to be the GTR (GTR + I + G) model. A phylogenetic tree reconstruction of T. cruzi was implemented applying Bayesian inference (BI) with the Mr. Bayes v.3.2 program. Ten Markov chains were performed for 8 million generations, and trees were sampled for every 1000 generations. Twenty-five percent of the sample trees were discarded, and the remaining trees were used to build up a consensus tree and calculation of posterior probabilities of clades. The result of Bayesian analyses was visualized using Figtree v1.4.2. T. rangeli concatenated sequences were used as root. Transformation of the leaves and schematically representation of the root were applied for visualization purposes.

\subsection{Haplotype Network Construction}

The Network 5.0 software [41] was used to construct all possible shortest least complex phylogenetic trees from concatenated sequence of both T. cruzi reference strains and Panamanian isolates using the median joining algorithm that permit multi-state data and setting the epsilon parameter of the algorithm. Additionally, we use the MP algorithm of Network software to get rid of all unnecessary median vectors and the star contraction option to look for any demographic expansion defining different color-coded nodes for each country of origin of the T. cruzi strains/isolates used herein.

\subsection{Estimation of Evolutionary Divergency between TcI Mitochondrial Sequences}

To assess the evolutionary divergence between T. cruzi TcI sequences, we initially calculated the $p$-distance and the number of base differences per sequence from between sequences using the evolutionary software Mega X [42]. Sixty-nine (29 from this study and 40 from reference strains) concatenated sequences were used to do the analysis including coding positions $1 \mathrm{st}+2 \mathrm{nd}+3 \mathrm{rd}$ and noncoding sites. All ambiguous positions were removed for each of the sequence pairs. There were a total of 2284 positions in the final dataset. Based on the $p$-distance and sequence similarity results, we grouped TcI haplotypes in five major geographical groups named: Brazil A, Brazil B, Brazil C, Andean countries, North-Central American and Western South American countries (NCWS). After grouping concatenated sequences, we estimated the evolutionary divergency between groups by assessing base differences per site from averaging over all sequence pairs between groups. To assess these differences, we computed differences between group mean distance by obtaining the $p$-distances and the number of differences between groups. The analyses were performed in 69 sequences including coding positions 1st +2 nd +3 rd and noncoding sites. After removing ambiguous positions, 2284 positions remained in the final dataset.3.

\section{Results}

We retrospectively genotyped 32 T. cruzi Panamanian isolates: 12 from humans with different clinical profiles, four from reservoirs and 16 from vectors collected in different endemic regions of Panama between 1965 and 2016 (Figure 1 and Table 1). Initial molecular 
analysis using the triple marker (mini-exon, HSP60 and GPI markers) confirmed that DTU TcI was the predominant T. cruzi genotype $(90.3 \% ; 28 / 31)$ found across all sources and time span. However, two human isolates from acute human cases (TCH1 and TCH10) and one (TCV15) from a secondary vector (P. geniculatus) displayed a non-TcI profile using this molecular approach. The mitochondrial MLST analysis further confirmed that TCH10 and TCV15 belong to the TcIII, and TCH1 to the TcVI DTUs (Figure 3).

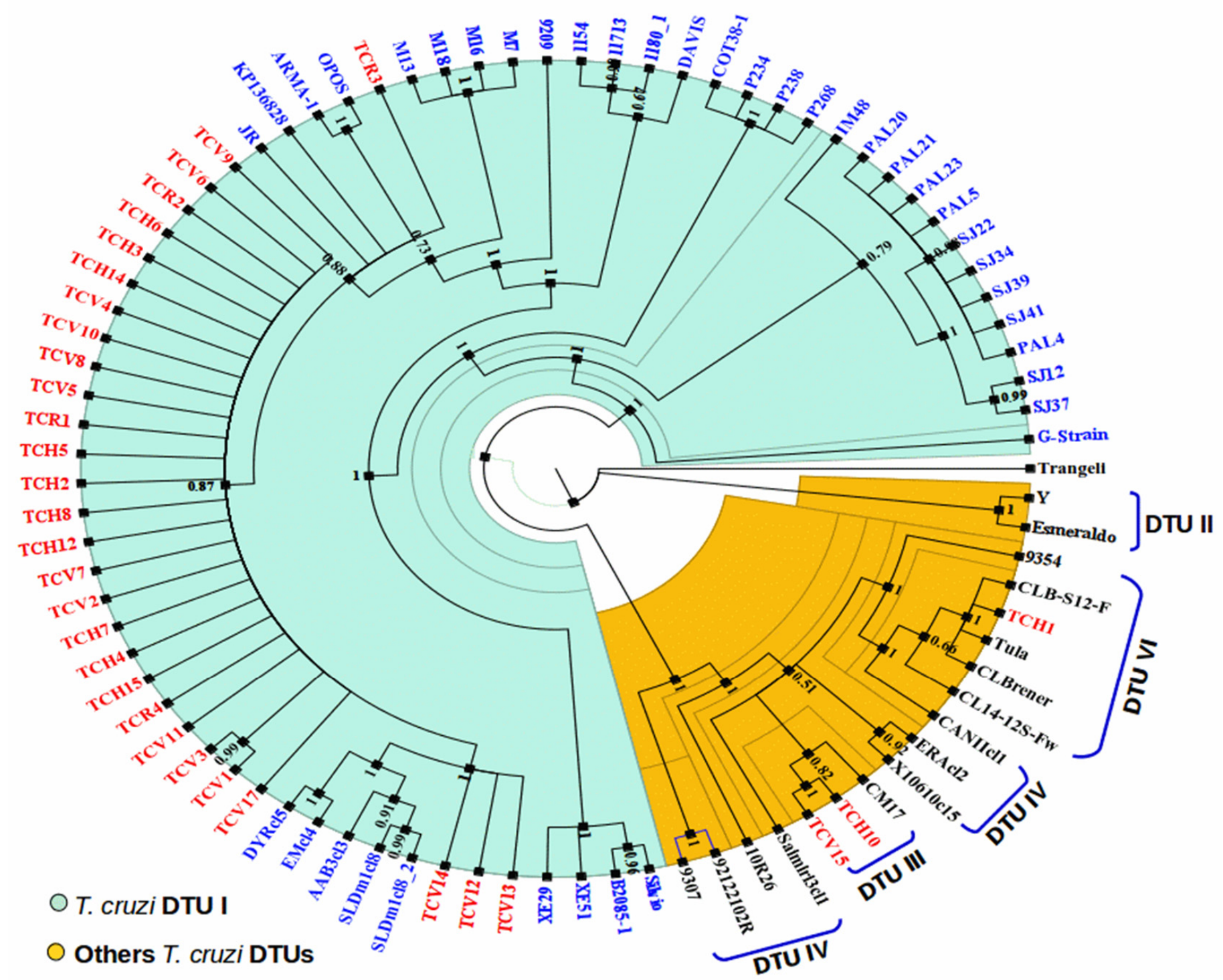

Figure 3. Phylogenetic tree inferred from Bayesian analysis showing relationships between 32 Trypanosoma cruzi isolates from Panama (in red color) and 55 reference T. cruzi strains across the Americas. TcI reference isolates are in blue color. The tree was constructed with the MrBayes v.3.2 program using concatenated mitochondrial sequences of six T. cruzi loci (ND1, COII, MURF1, CYT b, 12S rRNA and 9S rRNA). Ten Markov chains were proceeded for 8 million generations, and trees were sampled for every 1000 generations. Trypanosoma rangeli concatenated sequences were used as root.

\subsection{Phylogenetic Tree and Haplotype Network Results}

Reconstruction of a phylogenetic trees was conducted using the concatenated mitochondrial sequences of six loci (ND1, COII, MURF1, CYT b, 12S rRNA and 9S rRNA) from $87 \mathrm{~T}$. cruzi isolates, including the 32 from this study along with 55 reference isolates retrieved from the GenBank database (Figure 3). Complete sequence alignment of the 
concatenated genes from this study is available upon request. The inferred phylogenetic tree based on Bayesian analysis showed a distinct clustering among the different $T$. cruzi DTUs analyzed. Most Panamanian samples (29/32) grouped within the TcI cluster. Confirming the triple marker initial results, only three samples from this study (TCH1, TCH10 and TCV15) grouped outside the TCI cluster: TCH10 and TCV15 clustered with reference samples belonging to the TcIII DTU, and TCH1 with reference samples from the TcVI DTU (Figure 3).

Among the $29 \mathrm{TcI}$ Panamanian isolates, the majority were genetically homogenous and grouped together in a well-defined clade (Figure 3). However, two isolates from secondary vectors (TCV1 and TCV3) and three samples from the main Panamanian vector (TCV12, TCV13 and TCV14) showed some degree of genetic variability grouping in subclades within the TcI main Panamanian cluster, more closely related to reference isolates from Colombia. Interestingly, samples TCV12 and TCV13 originated from insects that were collected recently from non-traditional endemic regions located in the western side of Panama (Figure 1 and Table 1). Furthermore, sample TC3 that was isolated from an otter (Lontra longicaudis) in 1973, displayed a higher level of diversity clustering separately with TcI reference strains (OPOS and ARMA-1) isolated from opossums in southern USA.

Results from the haplotype network analysis among the concatenated TcI sequences (29 from this study and 40 reference isolates from different Chagas endemic countries), revealed the presence of 33 different haplotypes (Figure 4 and Table S2). Based on the nucleotide diversity and genetic distance observed among the haplotypes, five different regional groups (clusters) were evidenced: Andean region, Brazil A, Brazil B, Brazil C, and North and Central American Region-Western South American Countries (NCWS) (Figure 4, Tables S2-S4). As expected, due to its geographical proximity, Panamanian TCI isolates were positioned within this last regional group (NCWS), displaying eight different haplotypes (Haplotypes 18-25) circulating in endemic regions of the country (Figure 4 and Table S2). The Panamanian haplotypes (blue circles) formed a cluster of nodes $(n=6)$ surrounding a major node (Haplotype 18-TCV11) conformed by 19 identical sequences. This haplotype was the most frequent $(19 / 29 ; 65.5 \%)$ and widespread among the Panamanian isolates across the different regions and biological origin of the isolates. The other Panamanian haplotypes were less frequently detected (between 1 and 3 samples for each haplotype) and showed high relatedness with haplotype 18-TCV11, from which, most probably, they expanded. Consistent with the phylogenetic tree results, haplotype 25-TCR3 was genetically more distant from the major Panamanian haplotype cluster, and closer to haplotypes from Venezuela. It was represented by only one sample that originated from an otter; a wild animal not considered a common reservoir for Chagas disease. In general, Panamanian samples seem to have a distinct geographical position, more closely related to isolates from northern South America (particularly Colombia) and from Central America. As expected, samples from the most southern countries of Brazil, Bolivia and Argentina were more distantly related from the Panamanian samples.

\subsection{Nucleotide Divergence between Panamanian TcI Isolates and Reference Strains}

The calculation of $p$-distance and the number of base differences between mitochondrial concatenated sequences showed that the TcI Panamanian isolates were mostly homogenous. Twenty-six isolates out of 28 Panamanian isolates had $p$-distance value of zero and showed no nucleotide differences along the concatenated sequences after removing ambiguous positions for the analysis. However, isolates TCV17 and TCR3 were more divergent showing $p$-distance values of 0.002 and 0.001 , and nucleotides' differences of four and two nucleotides, respectively (Tables S4 and S5).

The divergency analysis also revealed differences between Panamanian isolates and reference strains used in this study. These genetic differences were more evident between haplotype sequences that seem to be more genetically divergent (Figure 4). For this reason, we decided to group the sequences based on the grade of divergency between them. As a result, five groups containing haplotypes with a high level of sequence similarity and 
being geographically related were found. The groups encompass haplotypes from Brazil (groups Brazil A, Brazil B and Brazil C), Andean countries (Andean countries group) and haplotypes from North and Central American countries along with Western South American Countries (NCWS group).

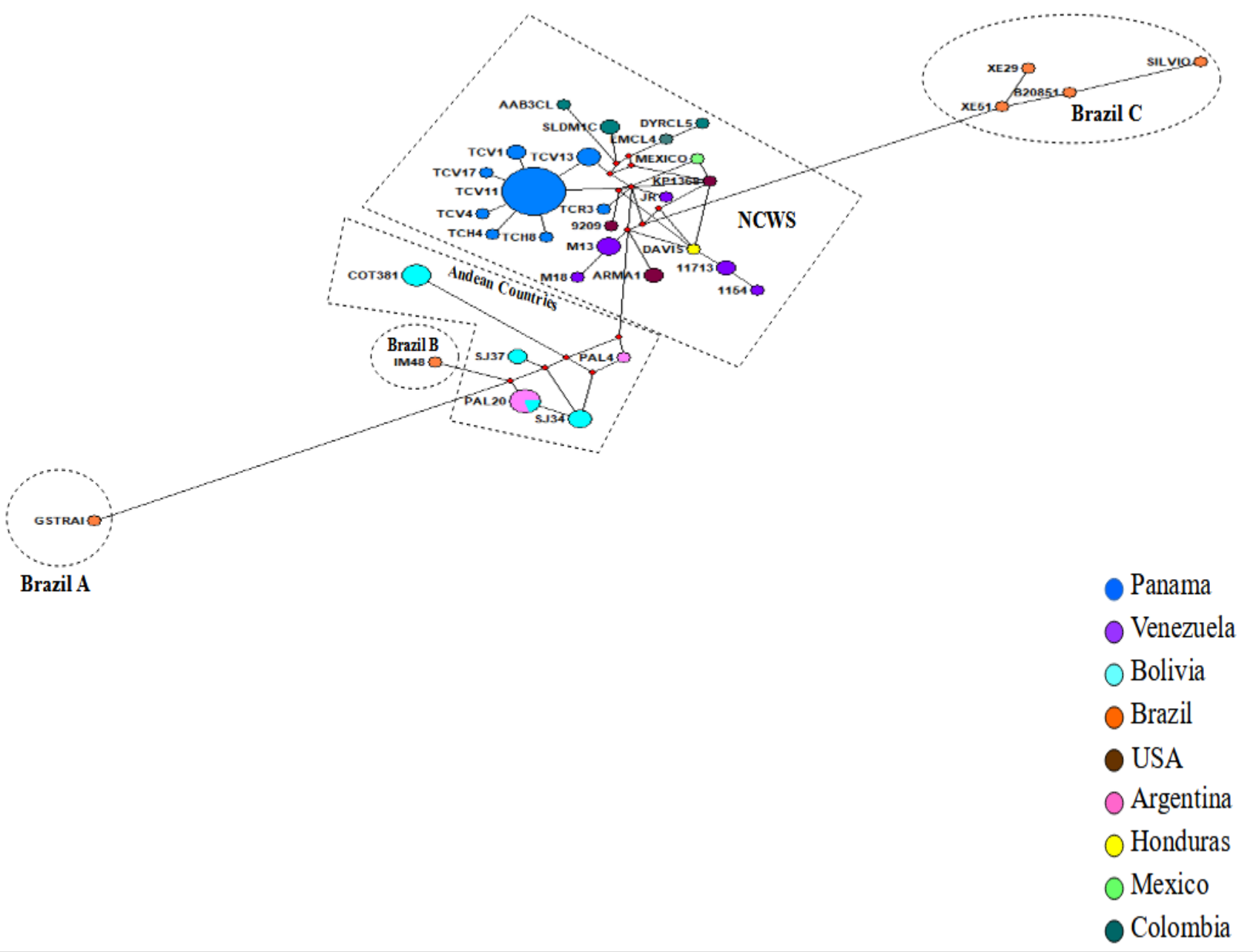

Figure 4. Haplotype network inferred by a median-joining method using concatenated mitochondrial sequences of six loci (ND1, COII, MURF1, CYT b, 12S rRNA and 9S rRNA) from 69 Trypanosoma cruzi TcI isolates, 29 from Panama (blue circles) and 40 reference T. cruzi strains from different endemic countries across the Americas. Circles represent a unique sequence haplotype with the color denoting the country origin and the size of the circle accounting for its frequency. The lengths of the lines connecting the haplotypes refer to the distance of relatedness. The small red circle represents the median vector, which can be interpreted as an unsampled sequence or an extinct ancestral sequence. The five clusters (Brazil A, Brazil B, Andean Countries, NCWS and Brazil C) are enclosed within dashed lines.

All haplogroups showed different levels of divergence with respect to the Panamanian TcI isolates (Tables S3-S5). The group Brazil A, consisting only of the G-strain, was the most divergent showing nucleotide difference between 44 to 48 nucleotides and $p$-distance values between 0.04 to 0.019 . Furthermore, Panamanian TcI isolates showed nucleotide differences from 22 to 33 nucleotides and $p$-distances varied from 0.10 to 0.15 compared with the Brazil $C$ haplogroup that consisted of four isolates from Brazil, including the Silvio strain. The strain IM48, the only member of Brazil B group, showed less differences with the Panamanian isolates than other Brazilian haplogroups. This strain had 22-27 nucleotide 
differences and $p$-distance values of 0.010 to 0.012 when compared to the Panamanian isolates. On the other hand, the Andean countries group was found to be less divergent than the Brazilians haplogroups when compared with Panamanian isolate sequences. This Andean haplogroup had nucleotide differences of 13 to 24 nucleotides along concatenated sequences and $p$-distance values between 0.006 to 0.012 . As expected, due to the geographic proximity, Panamanian isolates were more related to other members from the NCWS haplogroup which included isolates from North and Central America as well as isolates from Northern South America. Minor nucleotide differences and $p$-distance values were observed when compared with mitochondrial concatenated sequences inside this group. Nucleotide differences between 2 to 13 nucleotides and $p$-distance values of 0.001 to 0.006 were found between Panamanian isolates and reference strains belonging to this group.

\section{Discussion}

Since its formation about three million years ago, the Isthmus of Panama has been a biological corridor between North and South America for the interchange of reservoirs, vectors and the pathogens they have harbored (Figure 1), greatly shaping today's biological diversity observed in the country [43]. In this context, T. cruzi ancestors can be traced to approximately 5-7 million years ago when it separated from T. cruzi marinkellei $[44,45]$. Between 1-3 million years ago, coinciding with the formation of the land bridge joining South and North America 3.5-3.1 MYA [43], this T. cruzi ancestor further diversified to form the 7 major groups (DTUs) recognized today. Thus, the strategic position of Panama makes it an ideal site for conducting studies on the genetic composition and population structure of T. cruzi. The potential association between parasite genetic diversity and ecobiological, pathogenic and epidemiological characteristics of Chagas disease [31,32,46,47], further emphasizes the relevance of this analysis. Moreover, T. cruzi genetic diversity has the potential to confound the performance of serologic diagnosis [31,47]. It has recently emerged that certain haplotypes circulating in North and Central America are associated with negative or inconclusive serological results, despite clear molecular evidence for infection. This is most likely due to the antigenic diversity exhibited by different $T$. cruzi strains [47,48]. Issues with interpretation of serodiagnostic tests are further complicated in countries like Panama where other Trypanosomatidae, such as Leishmania spp. and the non-pathogenic T. rangeli, coincide with T. cruzi in common endemic areas $[10,18]$. Indeed, cross-reactivity between these divergent parasites has been described, particularly in individuals coinfected with Leishmania spp. [49].

Our exploration of the genetic diversity of Panamanian T. cruzi isolates derived from different biological samples over a span of 57 years (1960-2017) confirmed that TcI was the predominant DTU circulating in the country in strong agreement with previous studies conducted in Panama [21-25]. TcI was found across all biological samples, including patients with different clinical profiles and a fatal acute infection in a dog (Table 1), reinforcing the current view that TcI occurs in both domestic and sylvatic cycles in nature and may exhibit an important degree of pathogenicity [46]. Geographically, TcI is the predominant DTU in the Americas, dispersed widely from southern USA to northern Argentina. This DTU is found throughout the range of triatomine distribution infecting many different mammal hosts, including humans [28,32]. Moreover, TcI infections are common in patients with different clinical outcomes, including cardiomyopathy and death, from the Amazon basin [46,50], a region where Chagas' disease ecoepidemiology is similar to the one observed in endemic regions from Central Panama, especially as palms are hotspots for transmission between reservoir and triatomines.

Using our molecular genotyping approaches, it was also possible to unambiguously detect three isolates belonging to non-TcI genotypes: one TcVI and two TcIII. The TcVI DTU was detected in a patient from the central region of the country with an initial acute infection and a chronic evolution. In a recent whole-genome sequencing analysis of TcI isolates from six American countries, this TcVI isolate was mistakenly included as a TcI sample, and together with the highly virulent TcI Colombiana, was classified as 
an outlier [51]. In agreement with our results, a recent study assessing T. cruzi diversity through comparative genomics correctly assigned this isolate as TcVI [47]. Besides these findings, in the Mesoamerican region, TcVI has been previously described as infecting local vectors and humans from Mexico and Honduras [48,52-54], suggesting this DTU might be widely present, yet not frequently detected, across Mesoamerica. In the neighboring country of Colombia, TcVI has also been detected as infecting vector and human samples $[55,56]$, with a very low prevalence [57]. In general, TcVI has mainly been associated with domestic transmission cycles in the Southern cone of South America, where severe forms of Chagas disease and congenital transmission are frequently reported.

This study also identified TcIII in a Chagasic patient and in a vector species (P. geniculatus). TcIII infections have been mainly associated with terrestrial ecotopes and P. geniculatus $[58,59]$, which is a sylvatic vector that generally inhabits various vertebrate nests, especially the burrows of armadillos (Dasypodidae) and anteaters (Myrmecophagidae) [59], both common reservoirs found in the study area where the sample was isolated [18]. In Panama, P. geniculatus has also been reported with relative frequency to visit human dwellings located adjacent to forested areas, and the species has repeatedly been found infected with T. cruzi $[8,18,60]$. Although not frequently detected in humans, recent reports from Brazil and neighboring Colombia have described TcIII circulating in Chagasic patients with differing clinical forms [55,61]. We did not find TcIV in this study, although it is the most common secondary DTU reported in Central/North America [3].

The presence of non-TcI genotypes circulating in Panama was recently reported in a study conducted in a rural area from the eastern region of Panama where mixed infections (consisting of TcI coinfected with either TcII, TcV or TcVI) were found in chronic patients [25]. The molecular strategy employed in that study only permitted distinction between TcI and TcII/V/VI DTU groups. Unfortunately, we do not have isolates from this region to compare and confirm these interesting findings or to determine the exact DTUs implicated in the mix infections reported.

With few exceptions, the phylogenetic tree topography for most Panamanian TcI isolates displayed a high level of genetic homogeneity. One of the most divergent was TC3 that was isolated from an otter bled by one of our team members. It is difficult to speculate how this sylvatic semi-aquatic mammal that inhabits rivers in Panama became infected with T. cruzi. However, it can be argued that even though otters mainly feed on fish and crustaceans [62], the infection could have occurred via the ingestion of infected rodents or triatomine bugs present in their terrestrial burrows. Our network analysis was capable to capture a higher genetic diversity within Panamanian TcI isolates, displaying eight different haplotypes circulating in endemic regions of the country. Consistent with previous studies [3,29,47,51], the haplotype network also inferred a phylogeographic structuring among TcI isolates from different endemic regions. Inside this network, Panamanian TcI haplotypes clustered with the NCWS group that encompasses haplotypes belonging to geographical regions from North and Central America as well as haplotypes from the northernmost countries in South American (Colombia and Venezuela). Furthermore, results from the divergency analysis support this relationship, demonstrating that Panamanian TcI haplotypes are more genetically related to haplotypes from the NCWS group. It has been speculated that the tribe Rhodniini spread from the Amazon basin, passing through the Andes-Sierra Nevada to reach Colombia and then Central America, after the formation of the Panamanian isthmus around 2-4 MYA [63]. This might have opened the door to more recent speciation events in the genus Rhodnius in North and Central America regions, considering that the splits of Triatomines into Rhodnius and Triatoma occurred before the arrival of bats and rodents to South America [58]. TcI is mainly associated with the genus Rhodnius and shows a more generalized behavior regarding mammal host preferences. Therefore, the emergence of new Rhodnius species with diverse feeding patterns inhabiting sympatrically and/or allopatrically specific landscapes in Central and North America might have shaped the genetic structure of TcI in this region, as it has been suggested for T. rangeli [64-66]. The low genetic divergency found in TcI haplotypes from the NCWS 
group might be the result of recent vector-parasite interplay. Indeed, this low divergency among TcI from North and Central American region was also found when analyzing a set of T. cruzi isolates from the American continent by multi-locus microsatellite typing [29], supporting the results described herein and reinforcing the hypothesis that TcI originated from South America [29].

As a preliminary study assessing T. cruzi diversity in Panama, this study has a number of limitations. First, there is a clear geographical bias in the samples analyzed. Most of them were collected in the central region of the country (Figure 1), mostly because this area is more accessible and closer to research centers in Panama City with the technical capacity to isolate the parasite and conduct genotyping analysis. As a neglected infection throughout Latin America, many rural areas outside the central region also present suitable ecological conditions for T. cruzi transmission and have not been properly investigated, as demonstrated in the few isolated studies conducted in eastern and western regions of Panama [12,25,67,68]. Thus, genotyping T. cruzi samples from additional biological samples and wider geographic areas in the country would have allowed a better understanding of the genetic structure of T. cruzi in the country and exploring of the possible associations with the biology of the parasite and/or different epidemiological/pathogenic parameters. Second, it is possible that during parasite isolation and in vitro maintenance of parasites before the genotyping analysis, we missed some genetic diversity due to the clonal selection of particular lineages or intra-lineages that have overgrown the original population. In addition, DTUs isolated from blood do not necessarily reveal all DTUs in a particular host. Nevertheless, we detected different DTUs in the Panamanian samples as well as a considerable diversity within TcI isolates. Finally, there is a limited number of T. cruzi mitochondrial sequences from Central American countries available in public genetic databases to conduct a more robust phylogeographic regional analysis, including exploring possible association between TcI haplotypes and different host/vector species or transmission cycles.

Although our results revealed some degree of genetic heterogeneity among T. cruzi populations circulating in Panama, we may be far from knowing the extent of T. cruzi diversity in this country. This can partially be explained by the fact that simultaneous isolation of more than one population of T. cruzi from a single host (during potential mixed infections) is generally difficult, since different populations can produce different levels of parasitemia, growth in culture media and tissue tropism.

Additional studies that do not require isolation and culture of the parasites could help to resolve this problem. In this context, recent studies have proven that the use of complete maxicircle sequences is a superior phylogenetic marker for trypanosome taxonomic purposes and for studying the evolutionary history of trypanosomatids, resulting in phylogenetic trees with very high bootstrap support values $[69,70]$.

\section{Conclusions}

Our multi-locus sequence typing approach using six maxicircle genes has validated the predominance of $\mathrm{TcI}$ in Panama across different hosts and vector species. It has also confirmed the presence of TcIII and TcVI circulating in the country. The haplotype network analysis inferred considerably genetic diversity within Panamanian TcI haplotypes and revealed a geographical structuring among $\mathrm{TcI}$ isolates from different endemic regions in the Americas. This study adds novelty on the genetic diversity of T. cruzi circulating in Panama and complements regional phylogeographic studies regarding intra-TcI variations.

Supplementary Materials: The following supporting information can be downloaded at: https: / / www.mdpi.com/article/10.3390/microorganisms10020287/s1, Table S1: Accession numbers of T. cruzi maxicircle gene fragments reported in this study; Table S2: Haplotype regional groups (clusters) identified after analyzing concatenated mitochondrial sequences of five loci (ND1, COII, MURF1, CYT b, 12S rRNA and 9S rRNA); Table S3: Estimates of evolutionary divergency over sequence pairs between groups of haplotypes observed in this study; Table S4: Estimates of evolutionary divergence 
between mitochondrial sequences assessed by $p$-distance; Table S5: Number of base differences per sequence from between concatenated mitochondrial sequences.

Author Contributions: All authors participated actively in the study. Conceptualization, J.E.C., B.A.B. and A.S.; methodology, J.E.C., F.S., C.d.J. and V.P.; formal analysis, J.E.C., F.S., B.A.B. and A.S.; resources, B.A.B. and A.S.; writing-original draft preparation, J.E.C. and F.S.; review and editing, B.A.B. and A.S.; funding acquisition, J.E.C., B.A.B. and A.S. All authors have read and agreed to the published version of the manuscript.

Funding: This investigation received administrative and financial support from the Instituto Conmemorativo Gorgas de Estudios de la Salud in Panama and the Department of Immunology and Infectious Diseases from Harvard School of Public Health, USA. J.E.C. obtained a postdoctoral scholarship from SENACYT (BIDP-2012-013). J.E.C., F.S. and A.S. are members and received financial support from the Sistema Nacional de Investigación (SNI), SENACYT, Panama.

Institutional Review Board Statement: The study was conducted in accordance with the Declaration of Helsinki, and approved by the Institutional Review Board of the Dirección de Investigación y Desarrollo Tecnológico (DIDETEC) of the Instituto Conmemorativo Gorgas de Estudios de la Salud (ICGES) (protocol code: 037-DIDETEC-18; date of approval: January, 2018) for analyzing unidentified and coded archived Trypanosoma cruzi stocks isolated from humans, animals and vectors.

Informed Consent Statement: Not applicable.

Data Availability Statement: Complete sequence alignment of the concatenated genes from this study is available upon request. Accession numbers of nucleotide sequences for all gene fragments generated during this study are provided in Table S1.

Acknowledgments: This manuscript is dedicated to the memory of Octavio Sousa, a leading scientist in the fields of Parasitology and Tropical Medicine, and distinguished professor at the University of Panama. We thank Luis Chaves for the critical review of the manuscript and Alberto Cumbrera for map creation and figure addition.

Conflicts of Interest: The authors declare no conflict of interest. The funders had no role in the design of the study; in the collection, analyses, or interpretation of data; in the writing of the manuscript, or in the decision to publish the results.

\section{References}

1. Hotez, P.J.; Damania, A.; Bottazzi, M.E. Central Latin America: Two decades of challenges in neglected tropical disease control. PLoS Neglected Trop. Dis. 2020, 14, e0007962. [CrossRef] [PubMed]

2. Hotez, P.J.; Woc-Colburn, L.; Bottazzi, M.E. Neglected tropical diseases in Central America and Panama: Review of their prevalence, populations at risk and impact on regional development. Int. J. Parasitol. 2014, 44, 597-603. [CrossRef] [PubMed]

3. Dorn, P.L.; McClure, A.G.; Gallaspy, M.D.; Waleckx, E.; Woods, A.S.; Monroy, M.C.; Stevens, L. The diversity of the Chagas parasite, Trypanosoma cruzi, infecting the main Central American vector, Triatoma dimidiata, from Mexico to Colombia. PLoS Neglected Trop. Dis. 2017, 11, e0005878. [CrossRef] [PubMed]

4. Peterson, J.K.; Yoshioka, K.; Hashimoto, K.; Caranci, A.; Gottdenker, N.; Monroy, C.; Saldaña, A.; Rodriguez, S.; Dorn, P.; Zúniga, C. Chagas Disease Epidemiology in Central America: An Update. Curr. Trop. Med. Rep. 2019, 6, 92-105. [CrossRef]

5. Whitlaw, J.T.; Chaniotis, B.N., Jr. Palm Trees and Chagas' Disease in Panama. Am. J. Trop. Med. Hyg. 1978, 27, 873-881. [CrossRef]

6. Vasquez, A.M.; Samudio, F.E.; Saldaña, A.; Paz, H.M.; Calzada, J.E. Eco-epidemiological aspects of Trypanosoma cruzi, Trypanosoma rangeli and their vector (Rhodnius pallescens) in Panama. Rev. Inst. Med. Trop. Sao Paulo. 2004, 46, 217-222. [CrossRef]

7. Abad-Franch, F.; Lima, M.M.; Sarquis, O.; Gurgel-Gonçalves, R.; Sánchez-Martín, M.; Calzada, J.; Saldaña, A.; Monteiro, F.A.; Palomeque, F.S.; Santos, W.S.; et al. On palms, bugs, and Chagas disease in the Americas. Acta Trop. 2015, 151, 126-141. [CrossRef]

8. Rodriguez, I.G.; Loaiza, J.R. American trypanosomiasis, or Chagas disease, in Panama: A chronological synopsis of ecological and epidemiological research. Parasites Vectors 2017, 10, 1-16. [CrossRef]

9. Sousa, O.E.; Johnson, C.M. Frequency and Distribution of Trypanosoma cruzi and Trypanosoma Rangeli in the Republic of Panamá. Am. J. Trop. Med. Hyg. 1971, 20, 405-410. [CrossRef]

10. Saldaña, A.; Samudio, F.; Miranda, A.; Herrera, L.M.; Saavedra, S.P.; Cáceres, L.; Bayard, V.; Calzada, J.E. Predominance of Trypanosoma rangeli infection in children from a Chagas disease endemic area in the west-shore of the Panama canal. Mem. Inst. Oswaldo Cruz. 2005, 100, 729-731. [CrossRef]

11. Calzada, J.E.; Pineda, V.; Samudio, F.; Santamaría, A.M.; Cáceres, L.; Montalvo, E.; Bayard, V.; Saldaña, A.; Alvarez, D. Human Trypanosome Infection and the Presence of Intradomicile Rhodnius pallescens in the Western Border of the Panama Canal, Panama. Am. J. Trop. Med. Hyg. 2006, 74, 762-765. [CrossRef] [PubMed] 
12. Saldaña, A.; Pineda, V.; Martinez, I.; Santamaria, G.; Santamaría, A.M.; Miranda, A.; Calzada, J.E. A New Endemic Focus of Chagas Disease in the Northern Region of Veraguas Province, Western Half Panama, Central America. PLoS ONE 2012, 7, e34657. [CrossRef] [PubMed]

13. Basso, B.; Moretti, E.; Fretes, R. Vaccination with epimastigotes of different strains of Trypanosoma rangeli protects mice against Trypanosoma cruzi infection. Mem. Inst. Oswaldo Cruz. 2008, 103, 370-374. [CrossRef] [PubMed]

14. Marini, V.; Moretti, E.; Bermejo, D.; Basso, B. Vaccination with Trypanosoma rangeli modulates the profiles of immunoglobulins and IL-6 at local and systemic levels in the early phase of Trypanosoma cruzi experimental infection. Mem. Inst. Oswaldo Cruz. 2011, 106, 32-37. [CrossRef] [PubMed]

15. Basso, B.; Marini, V. Experimental Chagas disease. Innate immune response in Balb/c mice previously vaccinated with Trypanosoma rangeli. I. The macrophage shows immunological memory: Reality or fiction? Immunobiology 2014, 219, $275-284$. [CrossRef]

16. Aparicio-Burgos, J.E.; Zepeda-Escobar, J.A.; De Oca-Jiménez, R.M.; Estrada-Franco, J.G.; Barbabosa-Pliego, A.; Ochoa-García, L.; Alejandre-Aguilar, R.; Rivas, N.; Penuelas-Rivas, G.; Val-Arreola, M.; et al. Immune Protection against Trypanosoma cruzi Induced by TcVac4 in a Canine Model. PLoS Neglected Trop. Dis. 2015, 9, e0003625. [CrossRef]

17. Nuñez, J.M. Enfermedad de Chagas: Datos pertinentes y revisión de casos atendidos en el Hospital Santo Tomás 1955 a 1964. Arch. Med. Panameños 1966, 15, 35-47.

18. Sousa, O. Anotaciones sobre la enfermedad de Chagas en Panamá. Frecuencia y distribución de Trypanosoma cruzi y Trypanosoma rangeli. Rev. Biol. Trop. 1972, 20, 167-179.

19. Garisto-Risco, J.D.; Saldaña, A.; Zebede, S.; Calzada, J.E. Alteraciones cardiacas en pacientes seropositivos a la infección chagásica en Panamá. Rev. Esp. Cardiol. 2009, 62, 947-948. [CrossRef]

20. Blandón, R.; Guevara, F.J.; Johnson, C.M. Tránsito esofágico en pacientes con enfermedad de Chagas en Panamá. Arq. Gastroent. $1969,6,189-196$.

21. Sousa, O.E.; Samudio, F.; De Juncá, C.; Calzada, J.E. Molecular characterization of human Trypanosoma cruzi isolates from endemic areas in Panama. Mem. Inst. Oswaldo Cruz. 2006, 101, 455-457. [CrossRef] [PubMed]

22. Samudio, F.; Ortega-Barría, E.; Saldaña, A.; Calzada, J. Predominance of Trypanosoma cruzi I among Panamanian sylvatic isolates. Acta Trop. 2007, 101, 178-181. [CrossRef] [PubMed]

23. Brandão, A.; Samudio, F.; Fernandes, O.; Calzada, J.E.; Sousa, O.E. Genotyping of Panamanian Trypanosoma cruzi stocks using the calmodulin 3'UTR polymorphisms. Parasitol. Res. 2007, 102, 523-526. [CrossRef] [PubMed]

24. Saldaña, A.; Santamaría, A.M.; Pineda, V.; Vásquez, V.; Gottdenker, N.L.; Calzada, J.E. A darker chromatic variation of Rhodnius pallescens infected by specific genetic groups of Trypanosoma rangeli and Trypanosoma cruzi from Panama. Parasites Vectors 2018, 11, 423. [CrossRef] [PubMed]

25. Prescilla-Ledezma, A.; Blandon, R.; Schijman, A.G.; Benatar, A.; Saldaña, A.; Osuna, A. Correction: Mixed infections by different Trypanosoma cruzi discrete typing units among Chagas disease patients in an endemic community in Panama. PLoS ONE 2021, 16, e0250184. [CrossRef]

26. Zingales, B.; Andrade, S.G.; Briones, M.R.S.; Campbell, A.D.; Chiari, E.; Fernandes, O.; Guhl, F.; Lages-Silva, E.; Macedo, A.M.; Machado, C.R.; et al. A new consensus for Trypanosoma cruzi intraspecific nomenclature: Second revision meeting recommends TcI to TcVI. Mem. Inst. Oswaldo Cruz. 2009, 104, 1051-1054. [CrossRef]

27. Zingales, B.; Miles, M.A.; Campbell, D.A.; Tibayrenc, M.; Macedo, A.M.; Teixeira, M.M.; Schijman, A.G.; Llewellyn, M.S.; LagesSilva, E.; Machado, C.R.; et al. The revised Trypanosoma cruzi subspecific nomenclature: Rationale, epidemiological relevance and research applications. Infect. Genet. Evol. 2012, 12, 240-253. [CrossRef]

28. Brenière, S.F.; Waleckx, E.; Barnabé, C. Over Six Thousand Trypanosoma cruzi Strains Classified into Discrete Typing Units (DTUs): Attempt at an Inventory. PLoS Neglected Trop. Dis. 2016, 10, e0004792. [CrossRef]

29. Llewellyn, M.S.; Miles, M.A.; Carrasco, H.J.; Lewis, M.D.; Yeo, M.; Vargas, J.; Torrico, F.; Diosque, P.; Valente, V.; Valente, S.A.; et al Genome-Scale Multilocus Microsatellite Typing of Trypanosoma cruzi Discrete Typing Unit I Reveals Phylogeographic Structure and Specific Genotypes Linked to Human Infection. PLoS Pathog. 2009, 5, e1000410. [CrossRef]

30. Messenger, L.A.; Llewellyn, M.S.; Bhattacharyya, T.; Franzén, O.; Lewis, M.D.; Ramírez, J.D.; Carrasco, H.J.; Andersson, B.; Miles, M.A. Multiple Mitochondrial Introgression Events and Heteroplasmy in Trypanosoma cruzi Revealed by Maxicircle MLST and Next Generation Sequencing. PLoS Neglected Trop. Dis. 2012, 6, e1584. [CrossRef]

31. Zingales, B. Trypanosoma cruzi genetic diversity: Something new for something known about Chagas disease manifestations, serodiagnosis and drug sensitivity. Acta Trop. 2018, 184, 38-52. [CrossRef] [PubMed]

32. Telleria, J.; Tibayrenc, M. American Trypanosomiasis Chagas Disease: One Hundred Years of Research, 2nd ed.; Elsevier: Amsterdam, The Netherlands, 2017; pp. 1-826. Available online: https://www.elsevier.com/books/americantrypanosomiasis-chagasdisease/telleria/978-0-12-801029-7 (accessed on 15 December 2021).

33. Silveira, A.C. BID/OPS/IDRC/CNZ: Programa Regional para el Control de la Enfermedad de Chagas en América Latina; Iniciativa de Bienes Públicos Regionales, Ed.; BID: Montevideo, Uruguay, 2010; p. 242.

34. Hurtado, L.A.; Calzada, J.E.; Pineda, V.; González, K.; Santamaría, A.M.; Cáceres, L.; Wald, C.; Saldaña, A. Conocimientos y factores de riesgo relacionados con la enfermedad de Chagas en dos comunidades panameñas donde Rhodnius pallescens es el vector principal. Biomédica 2014, 34, 260-270. [CrossRef] [PubMed] 
35. Gottdenker, N.L.; Carroll, C.R.; Saldaña, A.; Calzada, J.E. Association of Anthropogenic Land Use Change and Increased Abundance of the Chagas Disease Vector Rhodnius pallescens in a Rural Landscape of Panama. Am. J. Trop. Med. Hyg. 2011, 84, 70-77. [CrossRef] [PubMed]

36. Gottdenker, N.; Chaves, L.F.; Calzada, J.E.; Saldaña, A.; Carroll, C.R. Host Life History Strategy, Species Diversity, and Habitat Influence Trypanosoma cruzi Vector Infection in Changing Landscapes. PLoS Neglected Trop. Dis. 2012, 6, e1884. [CrossRef]

37. Lewis, M.D.; Ma, J.; Yeo, M.; Carrasco, H.J.; Llewellyn, M.S.; Miles, M.A. Genotyping of Trypanosoma cruzi: Systematic Selection of Assays Allowing Rapid and Accurate Discrimination of All Known Lineages. Am. J. Trop. Med. Hyg. 2009, 81, 1041-1049. [CrossRef]

38. Costales, J.A.; Kotton, C.N.; Zurita-Leal, A.; Garcia-Perez, J.; Llewellyn, M.S.; Messenger, L.A.; Bhattacharyya, T.; Burleigh, B.A. Chagas disease reactivation in a heart transplant patient infected by domestic Trypanosoma cruzi discrete typing unit I (TcIDOM). Parasites Vectors 2015, 8, 435. [CrossRef]

39. Konechnikov, K.; Golosova, O.; Fursov, M.; Varlamov, A.; Vaskin, Y.; Efremov, I.; German Grehov, O.G.; Kandrov, D.; Rasputin, K.; Syabro, M.; et al. Unipro UGENE: A unified bioinformatics toolkit. Bioinformatics 2012, 28, 1166-1167. [CrossRef]

40. Darriba, D.; Taboada, G.L.; Doallo, R.; Posada, D. jModelTest 2: More models, new heuristics and parallel computing. Nat. Methods 2012, 9, 772. [CrossRef]

41. Polzin, T.; Daneschmand, S.V. On Steiner trees and minimum spanning trees in hypergraphs. Op. Res. Lett. 2003, 31, 12-20. [CrossRef]

42. Kumar, S.; Stecher, G.; Li, M.; Knyaz, C.; Tamura, K. MEGA X: Molecular Evolutionary Genetics Analysis across Computing Platforms. Mol. Biol. Evol. 2018, 35, 1547-1549. [CrossRef]

43. O'Dea, A.; Lessios, H.A.; Coates, A.G.; Eytan, R.I.; Restrepo-Moreno, S.A.; Cione, A.L.; Collins, L.S.; de Queiroz, A.; Farris, D.W.; Norris, R.D.; et al. Formation of the Isthmus of Panama. Sci. Adv. 2016, 2, e1600883. [CrossRef] [PubMed]

44. Tomasini, N.; Diosque, P. Evolution of Trypanosoma cruzi: Clarifying hybridisations, mitochondrial introgressions and phylogenetic relationships between major lineages. Mem. Inst. Oswaldo Cruz. 2015, 110, 403-413. [CrossRef] [PubMed]

45. Lewis, M.D.; Llewellyn, M.S.; Yeo, M.; Acosta, N.; Gaunt, M.W.; Miles, M.A. Recent, Independent and Anthropogenic Origins of Trypanosoma cruzi Hybrids. PLoS Neglected Trop. Dis. 2011, 5, e1363. [CrossRef] [PubMed]

46. Messenger, L.A.; Miles, M.A.; Bern, C. Between a bug and a hard place: Trypanosoma cruzi genetic diversity and the clinical outcomes of Chagas disease. Expert Rev. Anti. Infect. Ther. 2015, 13, 995-1029. [CrossRef] [PubMed]

47. Majeau, A.; Murphy, L.; Herrera, C.; Dumonteil, E. Assessing Trypanosoma cruzi Parasite Diversity through Comparative Genomics: Implications for Disease Epidemiology and Diagnostics. Pathogens 2021, 10, 212. [CrossRef] [PubMed]

48. Herrera, C.; Truyens, C.; Dumonteil, E.; Alger, J.; Sosa-Estani, S.; Cafferata, M.L.; Gibbons, L.; Ciganda, A.; Matute, M.L.; Zuniga, C.; et al. Phylogenetic Analysis of Trypanosoma cruzi from Pregnant Women and Newborns from Argentina, Honduras, and Mexico Suggests an Association of Parasite Haplotypes with Congenital Transmission of the Parasite. J. Mol. Diagn. 2019, 21, 1095-1105. [CrossRef] [PubMed]

49. Caballero, Z.C.; Sousa, O.E.; Marques, W.P.; Saez-Alquezar, A.; Umezawa, E.S. Evaluation of Serological Tests To Identify Trypanosoma cruzi Infection in Humans and Determine Cross-Reactivity with Trypanosoma rangeli and Leishmania spp. Clin. Vaccine Immunol. 2007, 14, 1045-1049. [CrossRef]

50. Aguilar, H.M.; Abad-Franch, F.; Dias, J.C.; Junqueira, A.C.; Coura, J.R. Chagas disease in the Amazon region. Mem. Inst. Oswaldo Cruz. 2007, 102, 47-56, Erratum in Mem. Inst. Oswaldo Cruz. 2007, 102, 1009. [CrossRef]

51. Talavera-López, C.; Messenger, L.A.; Lewis, M.D.; Yeo, M.; Reis-Cunha, J.L.; Matos, G.M.; Bartholomeu, D.C.; Calzada, J.E.; Saldaña, A.; Ramírez, J.D.; et al. Repeat-Driven Generation of Antigenic Diversity in a Major Human Pathogen, Trypanosoma cruzi. Front. Cell. Infect. Microbiol. 2021, 11, 614665. [CrossRef]

52. Dumonteil, E.; Ramírez-Sierra, M.J.; Pérez-Carrillo, S.; Teh-Poot, C.; Herrera, C.; Gourbiere, S.; Waleckx, E. Detailed ecological associations of triatomines revealed by metabarcoding based on next-generation sequencing: Linking triatomine behavioral ecology and Trypanosoma cruzi transmission cycles. Sci. Rep. 2018, 8, 4140. [CrossRef]

53. Villanueva-Lizama, L.; Teh-Poot, C.; Majeau, A.; Herrera, C.; Dumonteil, E. Molecular genotyping of Trypanosoma cruzi by next-generation sequencing of the mini-exon gene reveals infections with multiple parasite DTUs in Chagasic patients from Yucatan, Mexico. J. Infect. Dis. 2019, 219, 1980-1988. [CrossRef] [PubMed]

54. Murillo-Solano, C.; Ramos-Ligonio, A.; López-Monteon, A.; Guzmán-Gómez, D.; Torres-Montero, J.; Herrera, C.; Dumonteil, E. Diversity of Trypanosoma cruzi parasites infecting Triatoma dimidiata in Central Veracruz, Mexico, and their One Health ecological interactions. Infect. Genet. Evol. 2021, 95, 105050. [CrossRef] [PubMed]

55. Ramírez, J.D.; Guhl, F.; Rendón, L.M.; Rosas, F.; Marin-Neto, J.A.; Morillo, C.A. Chagas Cardiomyopathy Manifestations and Trypanosoma cruzi Genotypes Circulating in Chronic Chagasic Patients. PLoS Neglected Trop. Dis. 2010, 4, e899. [CrossRef]

56. Messenger, L.A.; Ramirez, J.D.; Llewellyn, M.S.; Guhl, F.; Miles, M.A. Importation of Hybrid Human-Associated Trypanosoma cruzi Strains of Southern South American Origin, Colombia. Emerg. Infect. Dis. 2016, 22, 1452-1455. [CrossRef] [PubMed]

57. Hernández, C.; Cucunubá, Z.; Florez, C.; Olivera, M.; Valencia-Hernandez, C.A.; Zambrano, P.; León, C.; Ramirez, J.D. Correction Molecular Diagnosis of Chagas Disease in Colombia: Parasitic Loads and Discrete Typing Units in Patients from Acute and Chronic Phases. PLoS Neglected Trop. Dis. 2016, 10, e0005112. [CrossRef] [PubMed]

58. Gaunt, M.; Miles, M. The ecotopes and evolution of triatomine bugs (triatominae) and their associated trypanosomes. Mem. Inst. Oswaldo Cruz. 2000, 95, 557-565. [CrossRef] [PubMed] 
59. Vivas, R.J.; García, J.E.; Guhl, F.; Hernández, C.; Velásquez, N.; Ramírez, J.D.; Carranza, J.C.; Vallejo, G.A. Systematic review on the biology, ecology, genetic diversity and parasite transmission potential of Panstrongylus geniculatus (Latreille 1811) in Latin America. Mem. Inst. Oswaldo Cruz. 2021, 116, e200528. [CrossRef]

60. Peterson, J.K.; Hashimoto, K.; Yoshioka, K.; Dorn, P.L.; Gottdenker, N.L.; Caranci, A.; Stevens, L.; Zuniga, C.; Saldaña, A.; Rodriguez, S.; et al. Chagas Disease in Central America: Recent Findings and Current Challenges in Vector Ecology and Control. Curr. Trop. Med. Rep. 2019, 6, 76-91. [CrossRef]

61. Martins, K.; Andrade, C.D.M.; Barbosa-Silva, A.N.; Nascimento, G.B.D.; Chiari, E.; Galvão, L.M.D.C.; da Câmara, A.C.J. Trypanosoma cruzi III causing the indeterminate form of Chagas disease in a semi-arid region of Brazil. Int. J. Infect. Dis. 2015, 39, 68-75. [CrossRef]

62. Souza, K.S.; Bastazini, V.A.; Colares, E.P. Feeding ecology of the Neotropical otter Lontra longicaudis in the Lower Arroio Grande River, southern Brazil. An. Acad. Bras. Cienc. 2013, 85, 285-294. [CrossRef]

63. Schofield, C.J.; Dujardin, J.P. Theories on the evolution of Rhodnius. Actual. Biol. 2017, 21, $183-197$.

64. Da Silva, F.M.; Junqueira, A.C.V.; Campaner, M.; Rodrigues, A.C.; Crisante, G.; Ramirez, L.E.; Caballero, Z.C.E.; Monteiro, F.A.; Coura, J.R.; Añez, N.; et al. Comparative phylogeography of Trypanosoma rangeli and Rhodnius (Hemiptera: Reduviidae) supports a long coexistence of parasite lineages and their sympatric vectors. Mol. Ecol. 2007, 16, 3361-3373. [CrossRef] [PubMed]

65. Salazar-Antón, F.; Urrea, D.A.; Guhl, F.; Arévalo, C.; Azofeifa, G.; Urbina, A.; Blandón-Naranjo, M.; Sousa, O.E.; Zeledón, R.; Vallejo, G.A. Trypanosoma rangeli genotypes association with Rhodnius prolixus and R. pallescens allopatric distribution in Central America. Infect. Genet. Evol. 2009, 9, 1306-1310. [CrossRef] [PubMed]

66. Dario, M.; Pavan, M.; Rodrigues, M.; Lisboa, C.; Kluyber, D.; Desbiez, A.; Herrera, H.; Roque, A.; Lima, L.; Teixeira, M.; et al. Trypanosoma rangeli Genetic, Mammalian Hosts, and Geographical Diversity from Five Brazilian Biomes. Pathogens 2021, 10, 736. [CrossRef]

67. Calzada, J.E.; Pineda, V.; Garisto, J.D.; Samudio, F.; Santamaria, A.M.; Saldaña, A. Human Trypanosomiasis in the Eastern Region of the Panama Province: New Endemic Areas for Chagas Disease. Am. J. Trop. Med. Hyg. 2010, 82, 580-582. [CrossRef]

68. Rodriguez, I.G.; Saldaña, A.; Gonzalez, K.; Pineda, V.; Perea, M.; Santamaría, A.M.; De Junca, C.C.; Chaves, L.F.; Calzada, E.J. Trypanosoma cruzi Infection in Rhodnius pallescens (Heteroptera: Reduviidae) Infesting Coyol Palms in the Dry Arch of Panamá. J. Med Èntomol. 2018, 55, 691-700. [CrossRef]

69. Kay, C.; Williams, T.A.; Gibson, W. Mitochondrial DNAs provide insight into trypanosome phylogeny and molecular evolution. BMC Evol. Biol. 2020, 20, 1-13. [CrossRef]

70. Berná, L.; Greif, G.; Pita, S.; Faral-Tello, P.; Díaz-Viraqué, F.; Souza, R.D.C.M.D.; Vallejo, G.A.; Alvarez-Valin, F.; Robello, C. Maxicircle architecture and evolutionary insights into Trypanosoma cruzi complex. PLoS Neglected Trop. Dis. 2021, 15, e0009719. [CrossRef] 